\title{
Economic Efficiency of Wheat Producers: The Case of Debra Libanos District, Oromia, Ethiopia
}

\author{
Kebebew Hundie Bezu ${ }^{1, a, *}$, Badassa Wolteji Chala ${ }^{2, b}$, Milkessa Wakjira ${ }^{3, c}$ \\ ${ }^{1}$ Ethiopian Biodiversity Institute, Addis Ababa, Ethiopia \\ ${ }^{2}$ Department of Economics, Ambo University, Ethiopia \\ ${ }^{3}$ Department of Economics, Ambo University, Ethiopia \\ *Corresponding author \\ A R T I C L E INFO A B S T R A C T \\ Research Article \\ Ethiopia has enormous potential for wheat production, yet it remains a net wheat importer. This \\ paper aims to examine the efficiency of wheat production in Debra Libanos district, Ethiopia. Two \\ stages sampling technique was used to randomly select 150 farmers for the study. A stochastic \\ production frontier and two-limit Tobit estimator was utilized in the study. The study reveals that \\ Received : 03/02/2021 \\ Accepted : 11/05/2021 \\ technical $(78.5 \%$, ), allocative $(85.6 \%)$, and economic $(66.7 \%)$ efficiencies. The yield gap was 5.13 \\ quintal/ hectare showing a room to increase efficiencies. The study identified the determinants of \\ wheat production efficiency in the area. Hence, to improve wheat production efficiencies \\ strengthen extension services, improved technology utilization, and proper land ploughing. Besides, \\ natural resource conservations that improve soil fertility should be the focus of the policymakers.
}

Keywords:

Cobb-douglas

Economic-efficiency

Ethiopia

Stochastic-frontier

Wheat

\section{Introduction}

In developing countries, agricultural production often falls short of its potential. Specifically, in sub-Saharan Africa, the majority of agricultural producers are poor, smallholder farmers with limited use of essential technologies such as sufficient improved seeds and fertilizers (Sheahan and Barrett, 2014).

In Ethiopia, the agricultural sector plays important roles in areas of food security, foreign exchange earnings, poverty alleviation, and employment creation. The sector accounts for about $35.8 \%$ of GDP, provides employment to more than $83 \%$ of the total population, generates about $79 \%$ of the foreign exchange earnings, and supplies raw materials for $70 \%$ of the industries in the country. Despite all these potentials, the sector failed to meet the food requirements of the growing population of the nation (UNDP, 2013). Consequently, Ethiopia is still a net importer of cereal crops mostly wheat. Yet, wheat is the most widely grown by smallholder farmers in the country. For example, about 1.7 million hectares (ha) of wheat was cultivated by about 4.2 million smallholder farmers. The average wheat yield, however, was about 27.4 qt per ha, during the 2017/18 cropping season (CSA, 2018).

Wheat productivity in Ethiopia is far below the world average, which is 33.2 qt per ha (FAS, 2018). Oromia region, the largest regional state in Ethiopia, covers $53 \%$ of the total area and $58 \%$ of national wheat production. In the North Shoa zone, which is one of the zones located in the Oromia regional state, wheat accounts for $21 \%$ in terms of production. Furthermore, $52 \%$ of smallholder farmers in the zone were wheat producers with productivity of just 25 qt. per ha. Wheat productivity was just 21 qt. per ha in Debra Libanos district, which is located within the North Shoa zone of Oromia regional state. As observed from the data, the minimum output of wheat was 6.5 qt per ha while the maximum output was 38.5 qt per ha. These figures were far less than both regional and national levels. In areas where there are efficiency variations, introducing new technology may not bring the expected impact, unless factors associated with efficiency variation among farmers are identified and acted upon (Alemayehu et al., 2012). 
Against this background, this study aims to analyze technical, allocative, economic efficiencies and their determinants of smallholder farmers in wheat production in Debra Libanos district, North Shoa zone, Oromia national regional state, Ethiopia.

\section{Research Methodology}

\section{Data and Data Sources}

The study primarily used a questionnaire to collect data that included institutional, socio-economic, farm characters, and demographic characteristics of the study area. A two-stage sampling technique was applied to select sample farmers. In the first stage, 3 kebeles (Kebeles are the smallest unit of administration in the Ethiopian government structure) were selected randomly from 7 wheat-producing kebeles. In the second stage, 150 sample farmers were selected using a simple random sampling technique based on probability proportional to the size of wheat producers in the 3 selected kebeles. The sample size is determined based on (Yamane, 1967) formula.

The simplified formula to calculate the sample size was:

$$
-\mathrm{n}=\frac{\mathrm{N}}{1+\mathrm{N}\left(\mathrm{e}^{2}\right.}
$$

where: $\mathrm{n}=$ sample size, $\mathrm{N}=$ total number of wheat producers in the study area; $\mathrm{e}=$ level of precision which is $8 \%$ and 1 is for designates probability of the event occurring. The formula was preferred since the target population is homogenous and $8 \%$ of the precision level was applied to manage all samples to minimize cost and time. The distribution of the sample farmers across the three kebeles is as follows: Goro Wertu (58); Wakene (53) and Dire Jibbo (39).

\section{Estimation Strategy}

In the study area, wheat is a rain-fed cereal crop that may suffer from random shocks such as drought and irregular rainfall. A farmer may deviate from the frontier not only because of measurement error, statistical noise but also because of economic efficiency variations. For this purpose, the stochastic frontier model (SPF) was used in the analysis of the economic efficiency of wheat production. The stochastic frontier model is preferred because of its capability to capture measurement error and other statistical noises influencing the shape and position of the production frontier. A stochastic production frontier proposed by Coelli and Battese (1995) in accordance with the original models proposed by Meeusen and Broeck (1977) is applied to cross-sectional data to determine economic efficiency. Hence, most recent studies on economic efficiencies such as Mustafa et al., 2017; Nigusu, 2018; Milkessa et al. (2019) have applied stochastic production frontier model to account for random noise. The general stochastic production model is specified as:

$$
y_{m}=f\left(X_{m} ; \beta\right)+\varepsilon_{m}
$$

$\mathrm{m}=1,2,3, \ldots, \mathrm{k}$, where $y_{m}$ the production of the $\mathrm{m}^{\mathrm{th}}$ sample farmer, $f\left(X_{m} ; \beta\right)$ was the convenient frontier production function e.g. Cobb-Douglas or Translog; $X_{m}$ is a vector of inputs used by the $\mathrm{m}^{\text {th }}$ sample farmer, $\beta$ is a vector of unknown parameters, $\varepsilon_{m}$ is a composed disturbance term made up of two error elements $\left(\mathrm{v}_{m}\right.$ and $\mathrm{u}_{m}$ ) and $\mathrm{k}$ represents the number of farmers who were involved in the survey.

Among the production function, Cobb-Douglas and translog production functions have been the most popularly used models in most empirical studies of agricultural production analysis. Some researcher argues that CobbDouglas functional form has advantages over the other functional forms in that it provides a comparison between the adequate fit of the data and computational feasibility. It is also convenient in interpreting the elasticity of production. In addition, it is very parsimonious with respect to degrees of freedom. According to Coelli (1995), Cobb-Douglas functional form has the most attractive feature such as its simplicity.

Cobb-Douglas model assumes unitary elasticity of substitution, constant production elasticity, and constant factor demand. If the interest is to analyze the efficiency measurement and not analyzing the general structure of production function, it has an adequate representation of technology and insignificant impact on the measurement of efficiency (Coelli et al., 2005). When farmers operate in small farms, the technology is unlikely to be substantially affected by variable returns to scale (Coelli, 1995). Moreover, the Cobb-Douglas production function has been employed in many types of research dealing with efficiency such as (Musa et al., 2015; Kifle et al., 2017; Mustafa et al., 2017; Nigusu, 2018; Milkessa et al, 2019). So, it was adopted for this study. Thus, the Cobb-Douglas frontier function was specified as follows:

$$
Y_{m}=A X_{1}^{\beta_{1}} X_{2}^{\beta_{2}} \ldots X_{n}^{\beta_{n}}
$$

The linear form of Cobb-Douglas production function for this study was defined as:

$$
\begin{gathered}
\ln \left(\mathrm{Y}_{\mathrm{m}}\right)=\beta_{0+} \sum_{\mathrm{n}=1}^{5} \beta_{\mathrm{n}} \ln \mathrm{X}_{\mathrm{mn}}+\varepsilon_{\mathrm{m}} \\
\ln \left(\mathrm{Y}_{\mathrm{m}}\right)=\beta_{0}+\beta_{1} \ln \text { SEED }+\beta_{2} \operatorname{lnLND}+\beta_{3} \operatorname{lnLAB}+ \\
\beta_{4} \operatorname{lnCHEMFER}+\beta_{5} \ln \mathrm{XXEN}+\varepsilon_{\mathrm{m}} \\
\varepsilon_{\mathrm{m}}=\mathrm{v}_{\mathrm{m}}-\mathrm{u}_{\mathrm{m}}
\end{gathered}
$$

Where, ln denotes the natural logarithm, n represents the number of inputs used, $m$ represents the $m^{\text {th }}$ farmer in the sample, $y_{m}$ represents observed wheat production of the $\mathrm{m}^{\text {th }}$ farmer, $\mathrm{X}_{\mathrm{mn}}$ denotes $\mathrm{n}^{\text {th }}$ farmer input variables was used in wheat production of the $\mathrm{m}^{\text {th }}$ farmer, $\beta_{0}$ represents intercept, $\beta_{1} ; \beta_{2}, \ldots, \beta_{5}$ stand for the vector of unknown parameters, $\varepsilon_{\mathrm{m}}$ a composed disturbance term makes up of two elements $\left(\mathrm{v}_{\mathrm{m}}\right.$ and $\left.\mathrm{u}_{\mathrm{m}}\right), \mathrm{v}_{\mathrm{m}}$ accounts for the stochastic effects beyond the farmer's control, measurement errors and other statistical noises and, $\mathrm{u}_{\mathrm{m}}$ captures the efficiency variation.

The dual cost function of the Cobb-Douglas production function was specified as:

$$
\ln C_{m}=\alpha_{0}+\sum_{n}^{5} \alpha_{n} \ln w_{m n}+\alpha_{n} \ln Y^{*}+V_{m}+U_{m}
$$


Where $\mathrm{m}$ refers to the $\mathrm{m}^{\text {th }}$ sample farmers, $\mathrm{n}$ was $\mathrm{a}$ number of input, $\mathrm{C}_{\mathrm{m}}$ was the minimum cost of production, $\mathrm{w}_{\mathrm{n}}$ denotes input prices, $\mathrm{Y}^{*}$ refers to wheat output which would be adjusted for noise, $\mathrm{v}_{\mathrm{m}}$ accounts for the stochastic effects beyond the farmer's control, measurement errors, as well as other statistical noises and $\mathrm{u}_{\mathrm{m}}$, captures the technical efficiency variation. (Sharma et al., 1999) suggests that the corresponding dual cost frontier of the Cobb-Douglas production functional form in the equation could be rewritten as:

$$
\begin{aligned}
& \mathrm{C}_{\mathrm{m}}=\mathrm{C}\left(\mathrm{w}_{\mathrm{m}} ; \mathrm{Y}^{*} ; \alpha\right)+\varepsilon_{\mathrm{m}} \\
& \mathrm{m}=1,2,3 \ldots \mathrm{K}
\end{aligned}
$$

Economically efficient input vector of the $\mathrm{m}^{\text {th }}$ firm $\mathrm{Xm}^{\mathrm{e}}$ is substituting the firms input prices and adjusted output level, a system of minimum cost input demand equation was expressed as:

$$
\frac{\partial \mathrm{C}}{\partial \mathrm{w}_{\mathrm{m}}}=\mathrm{X}_{\mathrm{m}}^{\mathrm{e}}\left(\mathrm{w}_{\mathrm{m}} ; \mathrm{Y}^{*} ; \beta\right)
$$

Then the TE scores of the given farmer were calculated as followed:

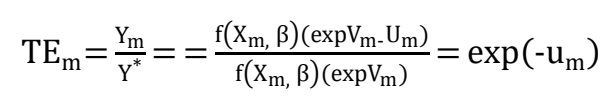

Where, $\mathrm{Y}^{*}=$ frontier output, $\mathrm{Y}_{\mathrm{m}}=$ actual output

The cost efficiency was defined in terms of the ratio of the observed cost to the corresponding minimum cost given the available technology. That was, cost efficiency $\left(C_{E}\right)$

$$
\mathrm{C}_{\mathrm{E}}=\frac{\mathrm{C}}{\mathrm{C}^{*}}=\exp \left(\mathrm{u}_{\mathrm{m}}\right)
$$

Where, $\mathrm{C}=$ actual production cost and $\mathrm{C}^{*}=$ the frontier total production cost or the least total production cost level. The AE was computed as the inverse of equation (10). Hence, farm-level AE would be obtained using the relationship:

$$
\mathrm{AE}_{\mathrm{m}}=\frac{1}{\mathrm{CE}}=\frac{\mathrm{C}^{*}}{\mathrm{C}}
$$

Where, $\mathrm{CE}=$ cost efficiency, $\mathrm{C}^{*}=$ minimum (efficient) cost and $\mathrm{C}=$ actual cost. A measure of farm-specific $\mathrm{EE}$ was obtained from the product of TE and EE:

$$
\mathrm{EE}_{\mathrm{m}}=\mathrm{AE}_{\mathrm{m}} \times \mathrm{TE}_{\mathrm{m}}
$$

In this study, economic efficiency was estimated from stochastic production by using a censored two-limit Tobit regression estimator on farm-specific independent variables that explained efficiency variation across wheat producers. The rationale behind using a two-limit Tobit regression estimator was that there were a number of farm units for which efficiency was bounded between 0 and 1 . Thus, the use of the Tobit estimator was intuitive because the parameter estimates were biased and inconsistent if OLS was utilized (Gujarati, 2004). This is because OLS underestimates the true effect of the parameters by reduced the slop as discussed in (Goetz, 1995). The degree of bias would also increase as the number of observations that take on the value of zero increases. This suggests that OLS regression was not appropriate and estimation with OLS would have led to biased parameter estimates. Therefore, the two-limit Tobit estimator offered the most preferred option and specified as follows:

$$
\mathrm{E}_{\mathrm{m},(\mathrm{TE}, \mathrm{AE}, \mathrm{EE})}^{*}=\delta_{0}+\sum_{\mathrm{L}=1}^{12} \delta_{\mathrm{L}} \mathrm{X}_{\mathrm{mL}}+\mathrm{u}_{\mathrm{m}}
$$

Where $m$ refers to the $m^{\text {th }}$ farm in the sample farmers; $\mathrm{L}$ is the number of factors affecting economic efficiency (TE); $E_{m}$ is economic efficiency scores representing the (economic efficiency) $\mathrm{TE}$ of the $\mathrm{m}^{\text {th }}$ farm. $\mathrm{E}_{\mathrm{m}}^{*}$ is the latent variable, $\delta_{0}$ is intercepting, $\delta_{\mathrm{L}}$ stands for unknown parameters to be estimated, $\mathrm{u}_{\mathrm{m}}$ is a random error term that is independently and normally distributed with mean zero and common variance. $\mathrm{X}_{\mathrm{mL}}$ represents demographic, institutional, socio-economic, and farm-related variables that were expected to affect economic efficiency. Denoting $\mathrm{E}_{\mathrm{m}}$ as the observed variables,

$$
E_{m}=\left[\begin{array}{ccc}
1 & \text { if } & E_{m}^{*} \geq 1 \\
E_{m}^{*} & \text { if } & 0<E_{m}^{*}<1 \\
0 & \text { if } & E_{m}^{*} \leq 0
\end{array}\right]
$$

\section{Results and Discussions}

Before analyzing the econometric results, three hypothesis tests were tested using generalized Likelihood Ratio (LR). First, the null hypothesis that all coefficients of the interaction terms in Cobb-Douglas specification are equal to zero was accepted. Hence, the Cobb-Douglas functional form was used to estimate the efficiency of the sample farmers in the study area. The second hypothesis tested indicates that the stochastic production frontier was an adequate representation of the data, given the corresponding OLS production function. Hence, the stochastic frontier model best fits the data under consideration. The third hypothesis test shows that independent variables are simultaneously equal to zero were not accepted at 5\% significance level. Hence, these variables simultaneously explain the sources of efficiency differences among the sample farmers.

\section{Estimation of The Production Function}

The result of the model showed that land, labor, chemical fertilizer and improved seed varieties utilizations have a positive and significant effect on wheat production. Hence, an increase in these inputs would increase the production of wheat significantly as expected. The coefficients of the production function are interpreted as elasticity since both the dependent and independent variables are in their natural logarithmic forms.

The value of sigma square $(\sigma 2)$ for the frontier of wheat output was 0.128 which was significantly different from zero and significant at $1 \%$ level of significance. The significant value of the sigma square indicates the goodness of fit and correctness of the specified assumption of the composite error terms distribution (Idiong, 2005 and Okoye et al., 2007). The ratio of the standard error of $\mathrm{u}^{2}$ $(\sigma \mathrm{u})$ to standard error $\mathrm{v}^{2}(\sigma \mathrm{v})$, known as lambda $(\lambda)$, is 2.488. Based on $\lambda$ value, gamma $(\gamma)$ which measures the 
effect of economic efficiency variation in the observed output can be derived

$$
\gamma=\frac{\lambda^{2}}{\left(1+\lambda^{2}\right)}=\frac{(2.488)^{2}}{\left(1+(2.488)^{2}\right)}=0.861
$$

The estimated value of gamma $(\gamma)$ was 0.861 which indicated that $86.1 \%$ of the total variation in wheat output is due to economic efficiency variation (Table 1).

Land allocated and chemical fertilizers utilized are found to be statistically significant at a $1 \%$ which implies that increasing the level of these inputs would increase wheat production in the study area. Moreover, the coefficient for land use was 0.390 , which implies that keeping other things the same, a $1 \%$ increase in the area of land allotted for wheat production results in $0.390 \%$ increase in wheat output. The utilization of chemical fertilizers also appeared to be an important factor with a coefficient of 0.305 . This implies that a $1 \%$ increase in chemical fertilizers increase wheat output by about $0.305 \%$ other thing kept constant. This result is consistent with the findings of (Musa et al., 2014).

Similarly, the coefficient of production with regard to improved seed utilization was 0.270 and significant at $1 \%$ significance level. It further indicates that a $1 \%$ increase in the quantity of improved seed used for wheat production results in a $0.27 \%$ increase in wheat output. This result is also in line with findings with (Musa et al., 2014 and Nigusu, 2018). Likewise, human labor was found to be statically significant at a 5\%. Specifically, a $1 \%$ increase in the quantity of labour for wheat production, keep other all inputs constant, results in $0.120 \%$ increase in wheat output. The result is consistent with the results obtained by (Musa et al., 2015; Desale, 2017).

The returns to scale analysis can serve as a measure of total factor productivity as elaborated in (Gbigbi, 2011). The coefficient was calculated to be 1.147 , which indicates increasing returns to scale. This in turn means that there is a potential for wheat producers to continue to expand their production where resource use and production is believed to be inefficient. In other words, a $1 \%$ increase in all inputs proportionally would increase the total production by $1.147 \%$. This result was consistent with the finding by (Kifle et al., 2017) who estimated the returns to scale to be 1.266 in the study of the efficiency of smallholder farmers in maize production in Oromia national regional state and 1.214 in the study of the efficiency of wheat production West Shoa zone. But a study done by (Desale, 2017) inefficiency sesame producers in Tigray, Ethiopia found returns to scale to be 0.926 which is decreasing returns to scale. The self-dual cost frontier function used to derive and estimate $\mathrm{AE}$ was given as follows:

$$
\begin{aligned}
\ln \left(C_{m n}\right)=5.400 & +0.001 \ln w_{m 1}+0.026 \ln w_{m 2} \\
& +0.017 \ln w_{m 3}+0.113 \ln w_{m 4} \\
& +0.071 \ln w_{m 5}+0.765 \ln \mathrm{Y}_{\mathrm{m}}^{*}
\end{aligned}
$$

Where, $\mathrm{C}_{\mathrm{mn}}$ is the minimum cost of wheat production; $\mathrm{Wm}_{1}$ is the average rental value of the land; $\mathrm{Wm}_{2}$ is the average costs of seed; $\mathrm{Wm}_{3}$ is the average costs of chemical fertilizer; $\mathrm{Wm}_{4}$ is the average costs of oxen and $\mathrm{Wm}_{5}$ is the average costs of labour; and $\mathrm{Y}_{\mathrm{m}}{ }^{*}$ is the average total amount of wheat produced in qt.

\section{Yield Gap Analysis}

Productivity can change due to differences in the production technology, efficiency of the production process, and environment in which production takes place. The yield gap always occurs due to TE variation among the farmers. So, analyzing the yield gap is important to estimate to what extent the production could be increased if all factors are controlled. It is computed as follows:

$$
-\mathrm{TE}_{\mathrm{m}}=\frac{\mathrm{Y}_{\mathrm{m}}}{\mathrm{Y}_{\mathrm{m}}^{*}}
$$

Then, solving for $\mathrm{Y}_{\mathrm{m}}^{*}$, the potential yield of each sample farmer was represented as:

$$
\mathrm{Y}_{\mathrm{m}}^{*}=\frac{\mathrm{Y}_{\mathrm{m}}}{\mathrm{TE}_{\mathrm{m}}}
$$

Where, $\mathrm{TE}_{\mathrm{m}}$, the TE of the $\mathrm{m}^{\text {th }}$ sample farmer in wheat production; $\mathrm{Y}_{\mathrm{m}}^{*}$ - the potential output of the $\mathrm{m}^{\text {th }}$ sample farmer in wheat production in qt per ha and $\mathrm{Y}_{\mathrm{m}}$ - the actual output of the $\mathrm{m}^{\text {th }}$ sample farmer in wheat production in $\mathrm{qt}$ per ha. Therefore,

$$
\text { yield gap (qt per ha) }=Y_{m}^{*}-Y_{m}
$$

In table 2 below, it was observed that the mean wheat yield difference between sample farmers due to economic efficiency variation was $5.13 \mathrm{qt}$ per ha. This implies that the sample farmers lost on average about 7,183.69 Birr per ha estimated at $(1 \mathrm{qt}=1400.33$ Birr, Birr is a Unit of Currency in Ethiopia).

\section{Efficiency Scores of Sample Farmers}

The mean TE of sample farmers was $78.5 \%$. Other studies support this finding. For example, Desale (2017) found mean TE of $71.4 \%$ for sesame producers in the Tigray region of Ethiopia, and Nigusu (2018) found a mean TE of $79 \%$ for teff producers in the Northern Shoa zone of Ethiopia. On average, if sample farmers in the study area operated at full TE level, they could increase their output by $17.8 \%$ derived from

$$
\left[\left(1-\frac{78.5}{95.5}\right) \times 100\right]
$$

from using the existing resources and level of technology. In other words, it implies that on average sample farmers in the study area can decrease their inputs (land, labor, oxen, chemical fertilizer, and seed) by $17.8 \%$ to get the output they are currently getting. The most technically inefficient farmer would have an efficiency gain of $69.21 \%$ derived from

$$
\left[\left(1-\frac{29.4}{95.5}\right) \times 100\right]
$$

to attain the level of the most TE farmer (Table 3).

The mean score of AE was $85.6 \%$ which indicated that on average sample farmers in the study area could increase wheat output by $12.4 \%$ obtained from

$$
\left[\left(1-\frac{85.6}{97.7}\right) \times 100\right]
$$


if farmers used the right inputs and produced the right output relative to input costs and output price. The most allocatively inefficient farmer had an efficiency gain of $79.53 \%$ derived from

$\left[\left(1-\frac{20}{97.7}\right) \times 100\right]$

to attain the level of the most AE farmers (Table 4). The mean EE $66.7 \%$ showed that there was a significant level of efficiency variation in the production process. The result also indicated that the farmer with an average level of EE would enjoy a cost saving of about $24.2 \%$ derived from

$\left[\left(1-\frac{66.7}{88}\right) \times 100\right]$ to attain the level of the most efficient farmer. The most economically not efficient farmer would have an efficiency gain of $82.61 \%$ derived from

$\left[\left(1-\frac{15.3}{88}\right) * 100\right]$

to attain the level of the most efficient farmer (Table 5).

Having analyzed efficiencies wheat productions, determinants of these efficiencies are analyzed. Here, a two-limit Tobit estimator was utilized to identify the determinants of technical efficiency (TE); allocative efficiency (AE), and economic efficiency (EE) of smallholder farmers' wheat production in the study area. Tobit is preferred to other estimators since TE, AE and EE are indices whose values are censored both from below and upper.

Table 1. Estimates of the Cobb-Douglas Frontier Production Function

\begin{tabular}{l|ccc}
\hline \multicolumn{1}{c|}{ Variables } & Parameters & MLE \\
\cline { 3 - 4 } Constant & $\beta_{0}$ & $2.454^{* * *}$ & Std. Err \\
LnSEED & $\beta_{1}$ & $0.270^{* * *}$ & 0.302 \\
LnLND & $\beta_{2}$ & $0.390^{* * *}$ & 0.071 \\
LnLAB & $\beta_{3}$ & $0.120^{* *}$ & 0.127 \\
LnCHEMFER & $\beta_{4}$ & $0.305^{* * *}$ & 0.053 \\
LnOXEN & $\beta_{5}$ & 0.062 & 0.053 \\
Elasticity & & 1.147 & 0.120 \\
Sigma square $(\sigma 2)$ & & 0.128 & 0.022 \\
Lambda $(\lambda)$ & & & 2.488 \\
Gamma $(\gamma)$ & & & 0.057 \\
Likelihood & & & \\
\hline
\end{tabular}

Note: $* * *$ and $* *$, significant at $1 \%$ and $5 \%$ level of significance, respectively

Table 2. Yield gap analysis

\begin{tabular}{l|cccc}
\hline \multicolumn{1}{c|}{ Variables } & Mean & Std. Dev. & Min & Max \\
\hline Actual qt per ha & 19.98 & 6.02 & 6.50 & 38.50 \\
TE (\%) & 78.5 & 0.12 & 29.4 & 95.5 \\
Potential (qt per ha) & 25.12 & 5.22 & 16.21 & 42.17 \\
Yield gap (qt per ha) & 5.13 & 2.58 & 1.25 & 15.40 \\
Money lost (birr per ha) & 7183.69 & 3614.22 & 1750.05 & 21565.6 \\
\hline
\end{tabular}

Source: Authors' computation (2019)

Table 3. Tobit and marginal effect results of the TE determinants

\begin{tabular}{|c|c|c|c|c|c|c|}
\hline \multirow{2}{*}{ Variables } & \multirow{2}{*}{ Parameters } & \multicolumn{2}{|c|}{ Tobit Result } & \multicolumn{3}{|c|}{ Computed marginal effect } \\
\hline & & Coef. & Std. Err. & $\partial \mathrm{E}(\mathrm{Y})$ & $\partial \mathrm{E}\left(\mathrm{Y}^{*}\right)$ & $\partial\left[\phi\left(Z_{U}-\varphi\left(Z_{L}\right)\right]\right.$ \\
\hline Constant & $\delta_{0}$ & $0.3114 * * *$ & 0.0722 & & & \\
\hline AGE & $\delta_{1}$ & $0.0031 * *$ & 0.0012 & 0.0031 & 0.0031 & 0.0002 \\
\hline EDUCLH & $\delta_{2}$ & 0.0020 & 0.0028 & 0.0020 & 0.0020 & 0.0002 \\
\hline SEX & $\delta_{3}$ & 0.0133 & 0.0214 & 0.0132 & 0.0130 & 0.0013 \\
\hline FAMSZE & $\delta_{4}$ & $0.0074 * *$ & 0.0033 & 0.0073 & 0.0073 & 0.0006 \\
\hline LIVESZE & $\delta_{5}$ & $0.0068 * * *$ & 0.0017 & 0.0068 & 0.0067 & 0.0005 \\
\hline FARSZE & $\delta_{6}$ & 0.0044 & 0.0070 & 0.0044 & 0.0043 & 0.0003 \\
\hline SOLFER & $\delta_{7}$ & 0.0104 & 0.0286 & 0.0103 & 0.0102 & 0.0010 \\
\hline CREDIT & $\delta_{8}$ & 0.0128 & 0.0127 & 0.0128 & 0.0127 & 0.0009 \\
\hline EXTEN & $\delta_{9}$ & $0.0221 * * *$ & 0.0073 & 0.0221 & 0.0218 & 0.0017 \\
\hline FREQPLOU & $\delta_{10}$ & $0.0240 * *$ & 0.0108 & 0.0239 & 0.0237 & 0.0018 \\
\hline OFFARM & $\delta_{11}$ & 0.0137 & 0.0172 & -0.0137 & 0.0135 & 0.0012 \\
\hline DTNMRKT & $\delta_{12}$ & 0.0002 & 0.0003 & 0.0002 & 0.0002 & 0.0000 \\
\hline
\end{tabular}

Note: $* * *$ and $* *$ refers to $1 \%$ and $5 \%$ significance level respectively,

$\frac{\partial \mathrm{E}(\mathrm{Y})}{\partial \mathrm{Xj}_{\mathrm{j}}}$ Overall changes, $\frac{\partial \mathrm{E}\left(\mathrm{Y}^{*}\right)}{\partial \mathrm{Xj}_{\mathrm{j}}} \quad$ Expected changes, $\frac{\partial\left[\phi\left(\mathrm{Z}_{\mathrm{U}}\right)-\varphi\left(\mathrm{Z}_{\mathrm{L}}\right)\right]}{\partial \mathrm{Xj}_{\mathrm{j}}}$ probability change 
Table 4: Tobit and marginal effect results of the AE determinants

\begin{tabular}{|c|c|c|c|c|c|c|}
\hline \multirow{2}{*}{ Variables } & \multirow{2}{*}{ Parameters } & \multicolumn{2}{|c|}{ Tobit Result } & \multicolumn{3}{|c|}{ Computed marginal effect } \\
\hline & & Coef. & Std. Err. & $\partial \mathrm{E}(\mathrm{Y})$ & $\partial \mathrm{E}\left(\mathrm{Y}^{*}\right)$ & $\partial\left[\phi\left(\mathrm{Z}_{\mathrm{U}^{-}} \varphi\left(\mathrm{Z}_{\mathrm{L}}\right)\right]\right.$ \\
\hline Constant & $\delta_{0}$ & 0.9466 & 0.1080 & & & \\
\hline AGE & $\delta_{1}$ & -0.0015 & 0.0018 & 0.0013 & 0.0010 & 0.0035 \\
\hline EDUCLH & $\delta_{2}$ & 0.0016 & 0.0042 & 0.0037 & 0.0011 & 0.0037 \\
\hline SEX & $\delta_{3}$ & $0.0550 *$ & 0.0320 & 0.0981 & 0.0411 & 0.0981 \\
\hline FAMSZE & $\delta_{4}$ & 0.0076 & 0.0049 & 0.0178 & 0.0052 & 0.0178 \\
\hline LIVESZE & $\delta_{5}$ & -0.0025 & 0.0026 & 0.0059 & 0.0017 & 0.0059 \\
\hline FARSZE & $\delta_{6}$ & $-0.0342 * * *$ & 0.0259 & 0.0799 & 0.0234 & 0.0799 \\
\hline SOLFER & $\delta_{7}$ & $0.0832 *$ & 0.0428 & 0.1112 & 0.0665 & 0.1112 \\
\hline CREDIT & $\delta_{8}$ & 0.0135 & 0.0190 & 0.0329 & 0.0091 & 0.0329 \\
\hline EXTEN & $\delta_{9}$ & 0.0085 & 0.0109 & 0.0198 & 0.0058 & 0.0198 \\
\hline FREQPLOU & $\delta_{10}$ & 0.0039 & 0.0161 & 0.0092 & 0.0027 & 0.0092 \\
\hline OFFARM & $\delta_{11}$ & 0.0262 & 0.0258 & 0.0568 & 0.0184 & 0.0568 \\
\hline DTNMRKT & $\delta_{12}$ & -0.0002 & 0.0005 & 0.0004 & 0.0001 & 0.0004 \\
\hline
\end{tabular}

Note: $* * *$ and $*$ refers to $1 \%$ and $10 \%$ significance level respectively.

Table 5: Tobit and marginal effect results of the EE determinants

\begin{tabular}{l|cccccc}
\hline \multirow{2}{*}{ Variables } & \multirow{2}{*}{ Parameters } & \multicolumn{2}{c}{ Tobit Result } & \multicolumn{3}{c}{ Computed marginal effect } \\
\cline { 2 - 6 } Constant & & Coef. & Std. Err. & $\partial \mathrm{E}(\mathrm{Y})$ & $\partial \mathrm{E}\left(\mathrm{Y}^{*}\right)$ & $\partial[\phi(\mathrm{ZU}-\varphi(\mathrm{ZL})]$ \\
AGE & $\delta_{0}$ & $0.3236^{* * *}$ & 0.0504 & & & 0.00000 \\
EDUCLH & $\delta_{1}$ & 0.0010 & 0.0009 & 0.0010 & 0.0010 & 0.00000 \\
SEX & $\delta_{2}$ & 0.0025 & 0.0020 & 0.0025 & 0.0025 & 0.00000 \\
FAMSZE & $\delta_{3}$ & $0.0399 * * *$ & 0.0150 & 0.0399 & 0.0399 & 0.00000 \\
LIVESZE & $\delta_{4}$ & 0.0006 & 0.0023 & 0.0006 & 0.0006 & 0.00000 \\
FARSZE & $\delta_{5}$ & $0.0039^{* * *}$ & 0.0012 & 0.0039 & 0.0039 & 0.00000 \\
SOLFER & $\delta_{6}$ & $-0.0254^{* * *}$ & 0.0049 & 0.0254 & 0.0254 & 0.00000 \\
CREDIT & $\delta_{7}$ & $0.0676^{* * *}$ & 0.0200 & 0.0676 & 0.0676 & 0.00000 \\
EXTEN & $\delta_{8}$ & 0.0040 & 0.0089 & 0.0040 & 0.0040 & 0.00000 \\
FREQPLOU & $\delta_{9}$ & $0.0138^{* * *}$ & 0.0051 & 0.0138 & 0.0138 & 0.00000 \\
OFFARM & $\delta_{10}$ & $0.0189 * *$ & 0.0075 & 0.0189 & 0.0189 & 0.00000 \\
DTNMRKT & $\delta_{11}$ & 0.0074 & 0.0120 & 0.0074 & 0.0074 & 0.0004 \\
\hline
\end{tabular}

Note: $* * *$ and $* *$ refers to $1 \%$ and $5 \%$ significance level respectively.

$\frac{\partial \mathrm{E}(\mathrm{Y})}{\partial \mathrm{Xj}}$ Overall changes, $\frac{\partial \mathrm{E}\left(\mathrm{Y}^{*}\right)}{\partial \mathrm{Xj}}$ Expected changes $\frac{\partial[\phi(\mathrm{ZU})-\varphi(\mathrm{ZL})]}{\partial \mathrm{Xj}}$ Probability change

Sex of the smallholder farmer (SEX) was one of statistically significant association was $\mathrm{AE}$ at $10 \%$ and $\mathrm{EE}$ at $1 \%$. The result indicated that male smallholder farmer was more efficient than female smallholder farmers. The possible reason is that male smallholder farmers carried out most of the activities on the farm and more frequent follow-up and supervision of their farm and they might accomplish the farming activities on time. Besides, male farmers are often willing to adopt new agricultural technologies. Specifically, a change in the dummy variable sex (0 to 1$)$ would increase the probability being of the farmers allocatively efficient by about $9.87 \%$ and the expected value of $\mathrm{AE}$ and $\mathrm{EE}$ by about $4.11 \%$ and $3.99 \%$ with an overall increase in the probability and levels of $\mathrm{AE}$ and $\mathrm{EE}$ by $9.81 \%$ and $3.99 \%$, respectively. This result is similar to the finding of (Milkessa et al., 2019). However, this result was contradictory to the finding of (Essa, 2011; Kifle et al., 2017).

Similarly, frequency of extension contact (EXTEN) enters the model of TE and EE with a positive coefficient at $1 \%$ significant level. A positive sign of this variable suggests that farmers have more frequency of extension contact could lead them to improvements in resource allocation, facilitates the practical use of modern techniques, adoption of improved agricultural production practices, and use inputs efficiently. More specifically, a unit increase in the number of extension contact would increase the probability of a farmer being technically efficient by $0.02 \%$ and the expected values of TE and EE by about $2.18 \%$ and $1.38 \%$ respectively, and the overall efficiency of TE and $\mathrm{EE}$ by about $2.21 \%$ and $1.38 \%$ respectively. This result was in line with the finding of (Kifle et al., 2017; Getachew et al., 2017). Other studies, however, found that extension contact negatively affects efficiency since extension workers are only concerned with increasing output and have not new skills and information to support the farmers (Musa, 2015; Mustafa et al., 2017). Pertaining to this study, the relative difference might be because of farmers who had high extension contact got new technology and correct management practices like timely sowing, weeding and can be used inputs as a proper way.

Likewise, livestock size (LIVESZE) entered the model pertaining to $\mathrm{TE}$ and $\mathrm{EE}$ with a positive coefficient at $1 \%$ of significant level supporting (Solomon, 2012; Mustafa et al., 2017; Getachew et al., 2017). This confirms the considerable contribution of livestock in reducing the cost of inputs in wheat production. In addition, given the importance of livestock in crop production as a source of draft power, income, and financing inputs the result seems intuitively appealing. More specifically, a unit increase in the size of livestock (TLU) would increase the probability 
being of technically efficient by about $0.05 \%$ and the expected values of technically and economically efficient by about $0.67 \%$ and $0.39 \%$ respectively. The overall increases in the probability and level of TE and EE by about $0.68 \%$ and $0.39 \%$ respectively. However, other researchers such as Desale (2017) argued that livestock size would negatively affect efficiency because livestock husbandry would compete for a resource with crop production and hence could not improve production efficiency. In the context of this study, the comparative disparity might be the effect of livestock size on efficiency was positive since the livestock in the crop production system was used as a source of income which in turn helps the farmers buy improved seed and fertilizers.

The tobit estimation result also shows that soil fertility (SOILFERT) entered the model corresponding to AE and $\mathrm{EE}$ at $10 \%$ and $1 \%$ level of significance respectively. This implies that farmers who have allocated fertile land for wheat production were more allocatively and economically efficient than their counterparts. Computed marginal effect result indicated that a change in the dummy variable, fertility status of the soil ( 0 to 1$)$ would increase the probability of the farmer being allocatively efficient by about $11.12 \%$ and the expected values of $\mathrm{AE}$ and $\mathrm{EE}$ by about $6.65 \%$ and $6.76 \%$ with an overall increase in the probability and levels of AE and EE by $11.12 \%$ and $6.76 \%$ respectively. This result is consistent with findings by (Getachew et al., 2017; Milkessa et al., 2019).

The empirical result shows that farm size entered the model pertaining $\mathrm{AE}$ and $\mathrm{EE}$ with negative coefficients at $1 \%$. This finding aligns with the popular law of diminishing returns in microeconomics. This could be because an increase in farm size diminishes the correctness of input use and hence inefficient utilization of farm inputs. The computed marginal effect result shows that a hectare increase in farm size would decrease the probability of a farmer being allocatively efficient by about $7.99 \%$ and the mean level of $\mathrm{AE}$ and $\mathrm{EE}$ by about $2.34 \%$ and $2.54 \%$ respectively with an overall decrease in the probability level of $\mathrm{AE}$ and $\mathrm{EE}$ by $7.99 \%$ and $2.54 \%$ respectively. This result is similar to the findings obtained by (Essa, 2011; Mustafa et al., 2017; Nigusu, 2018). In the context of the present study, relative disparity might be as increases farm size, decrease the timelines of inputs use making managing farm properly more difficult.

Interestingly, this study finds that frequency of ploughing (FREQPLOU) entered the model relating to TE and EE with statistically significant coefficients at $5 \%$. This could be because timely and proper land ploughing would make the soil suitable for crop growth. The computed marginal effect result shows that a unit increase in the frequency of ploughing would increase the probability of a farmer being technically efficient by $0.18 \%$ and the expected values of TE and EE by about $2.37 \%$ and $1.89 \%$ and the overall increase with the level of TE and EE by about $2.39 \%$ and $1.894 \%$ respectively. The result supports a finding by (Bekabil, 2011).

\section{Conclusions and Recommendations}

This study finds that wheat producers in the study area are not operating at full TE, AE, and EE levels. This implies there are opportunities to increase efficiencies in wheat production in the area. Among others, frequent extension contact, livestock size, and frequency of ploughing are among important factors that affect the efficiency of smallholder wheat farmers. This implies that farmers who had more extension contact with extension workers, own large livestock size, and frequently plough their wheat farmland was more economically efficient than their counterparts. Therefore, to improve the economic efficiency of smallholder wheat producers, adopting new technologies such as the use of improved seed and improving natural resource conservation to improve soil fertility shall be the focus of policymakers.

\section{Acknowledgments}

The authors would like to thank everyone who has contributed to this study, especially Debra libanos agricultural office experts. We would also like to thank Nigusu Abera for providing very constructive technical support for the study.

\section{References}

Alemayehu SP, Dorosh, Sinafkish A. 2012. Food and Agriculture in Ethiopia: Progress and Policy Challenges: Philadelphia Crop Production in Ethiopia: Regional Patterns and Trends.

Coelli TJ, Battese GE. 1995. A Model of Economic Efficiency Effects in a Stochastic Frontier Function for Panel Data. Empirical Economics, 20(2): 325-332.

Coelli TJ, Rao DSP, O'Donnell CJ, Battese GE. 2005. An Introduction to Efficiency and Productivity Analysis. Springer Science and Business Media.

Coelli TJ. 1995. Recent Development in Frontier Modelling and Efficiency Measurement. Australian Journal of Agricultural Economics, 39(3): 219-245.

CSA (Central Statistical Agency). 2018. Statistical Report on Area and Crop Production, (Private Peasant Holdings, Meher Season): Addis Ababa, Ethiopia.

FAS (Foreign Agricultural Service). 2018. World Agricultural Production. Market and trade Report of Foreign Agricultural Service/USDA Office of Global Analysis.

Gbigbi M. 2011. Economic efficiency of smallholder sweet potato producers in Delta State, Nigeria: A case study of Ughelli South Local Government Area. Research Journal of Agriculture and Biological Sciences, 7(2): 163-168.

Getachew W, Lemma Z, Bosena T. 2017. Economic Efficiency of Smallholder Farmers in Barley Production in Meket District, Ethiopia. Journal of Development and Agricultural Economics, 10 (10): 328-338.

Goetz JS. 1995. Markets, Transaction Costs and Selectivity Models in Economic Development. Prices, Products, and People: Analyzing Agricultural Markets in Developing Countries.

Gujarati DN. 2004. Basic Econometrics, 4th Ed. New Delhi: McGraw Hill. 1002p.

Idiong IC. 2005. Evaluation of Technical, Allocative, and Economic Efficiencies in Rice Production systems in cross River State, Nigeria, Ph.D. Dissertation, Department of Agricultural Economics, Michael Okpara University of Agriculture, Umudike, Nigeria.

Kifle D, Moti J, Belaineh L. 2017. Economic Efficiency of Farmers in Maize Production in Bako Tibe district, Ethiopia. Development country studies, 7(2): 80-86.

Meeusen W, van Den Broeck J. 1977. Efficiency Estimation from Cobb Douglas Production Functions with Composed Error. International Economics, 18(1), 435-444. 
Milkessa A, Endrias G, Fikadu M. 2019. Economic Efficiency of Smallholder Farmers in Wheat Production: In Abuna Gindeberet District, Oromia National Regional State, Ethiopia: Open Access Journal of Agriculture Research, 22 (2): $65-75$.

Musa H, Lemma Z, Endrias G. 2015. Measuring Technical, Allocative and Economic Efficiency of Maize Production Farming: Evidence from the Central Rift Valley of Ethiopia. Applied Studies in Agribusiness and Commerce, 9(3): 63-74.

Mustafa B, Mulugeta T, Raja KP. 2017. Economic Efficiency in Maize Production Ilu Ababor Zone, Ethiopia. Research Journal of Agriculture and Forestry, 5(12): 1-8.

Nigusu A. 2018. Technical Efficiency of Smallholder Teff Production. Open Acc J Agri Res: OAJAR-100015.

Nwachukwu I, Onyenweaku C. 2016. Allocative Efficiency among Fadama Fluted Pumpkin Farmers in Imo State Nigeria. Michael Okpara University of Agriculture, Nigeria, 13p.University.
Okoye BC, Onyenweaku CE, Asumugha GN. 2007. Economic Efficiency of Farmers Cocoyam Production in Anambra State, Nigeria. A Cobb-Douglas stochastic frontier production approach. Journal of Agricultural Research and Policies, 2(2): 27-31.

Sheahan M, Barrett C. 2014. Understanding the Agricultural Input Landscape in Sub- Saharan Africa: Recent Plot, Farmer, and Community-level evidence. World Bank Policy Research Working Paper 7014.

Solomon B. 2012. Economic Efficiency of Wheat Seed Production: The Case of Smallholders in Womberma Woreda of West Gojjam Zone. M.Sc. A Thesis Presented to the School of Graduate Studies of Haramaya University.

UNDP (United Nation Development Program). 2013. Building Resilience and Supporting Transformation in Ethiopia. Annual Report.

Yamane T. 1967. Statistics: An Introductory Analysis, $2^{\text {nd }}$ Ed., New York: Harper and Row. 